\title{
Imagem Institucional e Percepção de Desempenho de um Sindicato de Metalúrgicos
}

O presente artigo sumariza pesquisa que visou analisar a imagem como uma dimensão estratégica de um Sindicato de Metalúrgicos diante da dificuldade de obtenção de receitas após a promulgação da Reforma Trabalhista. O estudo, pretendeu especificamente identificar atributos considerados representativos da percepção pelos metalúrgicos da base sindical, quanto ao grau de atratividade e influência e capacidade de atuação. Para tanto, foi realizada uma pesquisa de campo que consultou cerca de 600 trabalhadores, de 34 empresas. As respostas dos inqueridos foram examinadas com base em análise fatorial determinou que principais fatores que influenciam a percepção quanto ao desempenho e imagem do sindicato.

Palavras-chave: Imagem; Percepção de Desempenho; Sindicato de Metalúrgicos; Análise Fatorial.

\section{Institutional Image and Perception of Performance of a Metalworkers Union}

\begin{abstract}
This article summarizes an research that aimed to analyze the image as a strategic dimension of a Metalworkers Union, in face of the difficulty of obtaining revenues after the promulgation of the Labor Reform. The study aimed specifically to identify attributes considered representative of the perception by the metalworkers of the union base, regarding the degree of attractiveness, influence and ability to act. To this end, a field survey was conducted that consulted about 600 workers from 34 companies. Respondents' responses were examined based on factor analysis determined which major factors influence the perception of syndicate performance and image.
\end{abstract}

Keywords: Image; Performance Perception; Metalworkers' Union; Factor analysis.

Topic: Terceiro Setor e Cooperativismo

Reviewed anonymously in the process of blind peer.
Received: 15/10/2019

Approved: 21/12/2019

Ronaldo Raemy Rangel (iD)

Fundação Getulio Vargas, Brasil

http://lattes.cnpq.br/0568681030105027

http://orcid.org/0000-0003-0195-0481

rrangel@fgvmail.br

Referencing this:

RANGEL, R. R.. Imagem Institucional e Percepção de Desempenho de um Sindicato de Metalúrgicos. Revista Brasileira de Administração Científica, v.10, n.4, p.145-157, 2019. DOI:

http://doi.org/10.6008/CBPC2179-684X.2019.004.0010 


\section{INTRODUÇÃO}

A reforma trabalhista aprovada em 2017, alterou de maneira significativa como sindicatos obtinham receitas para custear suas atividades. E não nos referimos aqui aos sindicatos sem expressão ou sem força de autuação, mas, sim, daqueles com militância, que de fato representavam os trabalhadores. A reforma trabalhista trouxe a facultatividade da contribuição sindical, aliada à necessidade de autorização expressa do referido desconto pelos empregados o que implica na necessidade de os sindicatos organizados buscarem apoio e comprometimento dos trabalhadores que representam.

Por outro lado, a reforma incentivou uma certa competição entre os sindicatos, vez que há agora a possibilidade do trabalhador escolher o sindicato que melhor o beneficiará. Assim a imagem e a reputação de cada sindicato passaram a ser de extrema relevância para manter apoio e representatividade junto as categorias profissionais.

Sabe-se que por meio de tecnologias desenvolvidas com foco na avaliação do desempenho organizacional é possível que, não só as empresas, mas qualquer modelo de organização ou de instituições elaborem diagnósticos externos que orientem seu planejamento e suas metas as quais não pode abstrair o proeminente papel desempenhado pela sua imagem corporativa ou institucional.

Embora não se trate de uma análise sistematicamente realizada pelas organizações sindicais no Brasil, a imagem corporativa (ou institucional) há muito tem sido investigada, por acadêmicos do marketing e de disciplinas afins, como fundamento essencial na construção de vantagem competitiva sustentável. Com efeito, trabalhos alicerçados sobre imagem e reputação corporativa podem determinar os principais fatores que influenciam a percepção dos agentes envolvidos - no caso em tela do público consumidor dos serviços ofertados pelo sindicato - quanto ao desempenho da organização, verificando, então, se sua imagem corporativa participa como dimensão de destaque.

O presente artigo tem exatamente esta finalidade, ou seja, identificar a imagem corporativa e institucional de um dos vários Sindicato dos Metalúrgicos estabelecidos no Brasil e em que sentido tal imagem pode colaborar na formação de políticas e dos serviços que oferta aos trabalhadores sindicalizados e, mesmo, a categoria como um todo e, por via de consequência, em seu desempenho institucional. Para tanto, fez-se necessária à utilização de coleta e tratamento de informações de fontes primárias, obtidas por intermédio de adoção de questionário estruturado e auto administrado como instrumento de pesquisa e a análise fatorial como ferramenta estatística para tratamento destes dados.

\section{REVISÃO TEÓRICA}

A imagem corporativa há muito desperta interesse entre os acadêmicos das mais variadas áreas. Embora apresente definições diversas, que diferem conforme a formação do estudioso, existe consenso quanto à sua primazia não só para as empresas comerciais, como para as instituições públicas, ou para organizações de caráter semi-público ${ }^{1}$.

${ }^{1}$ Nos referimos aqui aquelas instituições privadas que executam atividades de interesse público. 
Na concepção de Pierre Martineau “padrões subjetivos de conhecimento constituem a interface entre a realidade externa e o ser humano. Como a mente não consegue administrar muitos conteúdos complexos, ela abstrai e simplifica de modo a só considerar os significados julgados relevantes" (MARTINEAU, 1958). É, nesse contexto, que se destaca a importância da imagem corporativa ou institucional, uma vez que sintetiza um conjunto de significados complexos. Paralelamente, a imagem influencia ativamente a edificação da reputação corporativa, que é, indubitavelmente, um elemento de destaque em investigações acerca de organizações sindicais como é o caso do SINDMETAL - Sindicato dos Metalúrgicos em tela.

Assim, a avaliação da imagem percebida pelos distintos públicos-alvo do SINDMETAL passa a ter posição de relevo, uma vez que participa não apenas da formação de expectativas quanto a seu desempenho futuro, como também na avaliação de sua atuação e na construção de sua reputação. A literatura recente voltada para atuação das organizações que atuam em movimentos sociais, notadamente, nos movimentos sindicais, considera que estas instituições devem ter o firme propósito de manter elevados níveis de qualidade e diversificação para diferenciar sua atuação daquelas promovidas por congêneres com baixa expressão ou por entidades políticas de cunho assistencialista. Para tanto, deve conduzir uma política estratégica e uma prática centrada na excelência e performance dos serviços com que opera, sem perda do foco de envolvimento político com os anseios médios da categoria.

Assim, embora reafirmando a importância dos referidos elementos e do nexo causal que mantêm com a reputação corporativa, temos certo que é a interação complexa da imagem com as demais dimensões relevantes da organização sindical, que definirão a sua reputação junto ao público, notadamente ao sindicalizado.

O presente artigo visou verificar qual vem a ser a imagem corporativa do SINDMETAL e se ela participa, de fato, como dimensão fundamental na percepção do público quanto ao desempenho do sindicato, determinando não apenas as suas variáveis constituintes, como as variáveis relacionadas às demais dimensões.

\section{Revisão de literatura}

A literatura sobre imagem corporativa é caracterizada por apresentar contribuições de diferentes áreas acadêmicas, como o marketing e a estratégia empresarial, entre outras. Por essa razão, há várias definições para o mesmo conceito, que dependem da perspectiva do pesquisador. Para a finalidade da presente investigação, julgamos mais apropriado, com base na classificação proposta por Gotsi et al. (2001), reunir os estudos produzidos pela área de marketing e de disciplinas correlatas em dois grandes grupos, considerando a relação entre imagem e reputação corporativa como seu marco distintivo. Dessa forma, podemos incluir no primeiro grupo aqueles estudos que consideram a imagem como sinônimo de reputação corporativa, ao passo que agregaríamos, num segundo grupo, os trabalhos que os julgam conceitos distintos.

Convém tecermos algumas considerações acerca do nosso critério de organização para o trabalho realizado. Elegemos a relação entre a imagem e a reputação corporativa como elemento diferenciador das contribuiç̧̃es da área sindical, não só como recurso para sua organização, mas, sobretudo, para realçar uma 
questão de grande relevância. Ela se refere ao fato de que a imagem corporativa não é tratada pela literatura sobre o tema avaliação sindical, enquanto a reputação tem sido crescentemente estudada pelos acadêmicos da área. Nos trabalhos previamente examinados, a reputação corporativa é concebida com a acepção de credibilidade, havendo, inclusive, revezamento dos termos em um mesmo trabalho.

\section{Imagem e reputação corporativa enquanto conceitos distintos}

Fombrun et al. (1990) supõe que as companhias competem por reputação em um mercado caracterizado por informação imperfeita, onde os seus distintos públicos prestam atenção, segundo seus interesses, aos sinais de mercado, contábeis, institucionais e estratégicos referentes à corporação. A reputação resultaria das múltiplas imagens construídas no decorrer do tempo pelos públicos-alvo. Como a reputação favorável sinaliza uma qualidade superior para os consumidores, possibilita a cobrança de preçosprêmio. Atrai também melhores candidatos às vagas disponíveis na corporação, facilita o seu acesso ao mercado de capitais e exerce atração sobre investidores.

De fato, segundo Caruana (1997), gera-se uma inconsistência conceitual quando reputação e imagem corporativa são tratadas como sinônimos. Essa contradição estaria fundamentada na definição de imagem e de reputação como percepção global da corporação por seus distintos públicos externos. Para que os referidos conceitos se sobrepusessem, significando percepção global, seria necessário que os diversos públicos percebessem os mesmos sinais emitidos pela organização, que contêm atributos representativos de suas características essenciais e de suas ações passadas, bem como lhes atribuíssem os mesmos pesos. Todavia, como a corporação pode desfrutar de uma reputação forte junto a determinado público e possuir uma reputação frágil junto a outro, não haveria, na visão de Caruana (1997), coincidência entre o conceito de imagem e o de reputação corporativa. A reputação corporativa seria construída ao longo do tempo, enquanto a imagem é a percepção em um determinado momento do tempo.

De acordo com Balmer (1998), a imagem difere da reputação corporativa na medida em que a primeira está relacionada 'às opiniões mais recentes' do público acerca de determinada organização, enquanto a última representa um julgamento de valor sobre as qualidades da corporação, sendo 'construída ao longo do tempo'. Ou seja, a reputação corporativa teria uma dimensão histórica, refletindo a percepção em relação à consistência de ação e ao comportamento da corporação no transcurso do tempo.

Alessandri (2001a) afirma que a identidade corporativa está relacionada à apresentação estrategicamente planejada e intencional pela própria empresa, com vistas a criar uma imagem corporativa positiva na mente do público. A imagem corporativa seria, assim, a percepção da firma por parte do público. Segundo a autora, "sustentada durante um período considerável, as impressões repetidas da imagem corporativa modelam a reputação" (ALESSANDRI, 2001b). Em outras palavras, a reputação seria determinada pela imagem corporativa percebida ao longo do tempo.

\section{METODOLOGIA}

Com base na bibliografia pré-analisada, pode-se constatar que o problema básico para o SINDMETAL 
é verificar se a imagem corporativa constitui uma dimensão que participa na percepção dos públicos notadamente o trabalhador já sindicalizado e aqueles que são potenciais sindicalizados - sobre seu desempenho. Para atingir esse objetivo, procuramos responder às seguintes perguntas: Quais são os principais fatores que influenciam a percepção quanto ao desempenho do SINDMETAL?. A imagem institucional participa como uma dimensão relevante na percepção quanto ao desempenho do SINDMETAL?.

A pesquisa descrita neste artigo se caracterizou por ser exploratória, uma vez que há pouco conhecimento acumulado na área, não sendo aconselhável o estabelecimento de hipóteses. Com relação à pesquisa exploratória, Vergara (2009) observa que: “Por sua natureza de sondagem, não comporta hipóteses que, todavia, poderão surgir durante ou ao final da pesquisa". Para responder as perguntas da pesquisa empregamos, como ferramenta estatística básica, a análise fatorial.

\section{Amostra}

Utilizamos a estratégia de pesquisa de analisar a percepção da imagem corporativa do SINDMETAL entre os metalúrgicos da base sindical, independentemente de serem ou não sindicalizados. Para tanto nos concentramos em algumas das principais empresas do setor na região de atuação, por serem as que mais concentram trabalhadores ligados ao movimento político dos metalúrgicos. Foram inquiridos trabalhadores que demonstraram conhecer previamente as atividades promovidas pelo SINDMETAL, dado que por isso possuírem melhor percepção quanto as possibilidades efetivas da ação da entidade.

A amostra elaborada considerou um erro amostral de $4 \%$ e um intervalo de confiança de $95 \%$, sendo constituída por 586 (quinhentos e oitenta e seis) indivíduos escolhidos aleatoriamente em 34 locais (empresas), número de elementos representativo do universo da categoria pesquisada e suficiente para analisar a percepção da imagem corporativa quanto ao SINDMETAL de modo a ampliar a capacidade de compreensão dos principais fatores que influenciam a percepção quanto ao seu desempenho.

\section{Coleta de dados}

Como técnica de coleta de dados primários, utilizamos o já citado questionário estruturado e auto administrado. O questionário foi constituído de afirmativas relativas ao diagnóstico da percepção que o sindicato tem sobre si mesma. Tal percepção aqui caracterizada como identidade foi estabelecida a partir de informações previamente coletadas entre diretores do SINDMETAL que definiu os chamados valores institucionais que foram sendo erguidos e se consolidando ao longo da história política recente do SINDMETAL. Tais valores ora utilizados à guisa de identidade são, com efeito, os determinantes da atuação e dos compromissos assumidos pelo SINDMETAL perante a categoria profissional. Explicitam, portanto, como o sindicato se projeta para fora e, principalmente, como gostaria de ser percebida.

Os questionários utilizados no inquérito empregaram a escala Lickert de 5 pontos, com respostas graduadas segundo 'concordo muito' a 'discordo muito' e os escores foram atribuídos de tal modo que a direção de atitude (favorável para desfavorável) fosse consistente para todas as afirmativas. Quando atribuído 1 para 'concordo integralmente' em afirmativas favoráveis, o mesmo valor será atribuído para 
'discordo integralmente' em afirmativas desfavoráveis. O objetivo do uso de questões favoráveis e desfavoráveis, balanceadas ao longo do questionário, é o de minimizar o erro sistemático.

As aludidas afirmativas procuraram avaliar a percepção do respondente quanto à atuação do SINDMETAL, quanto à qualidade dos serviços que oferecem; quanto aos serviços de atendimento ao público; quanto a conduta de ação política; e quanto à sua imagem, nos moldes seguidos pelos pesquisadores de imagem corporativa. No tocante à avaliação da imagem corporativa, consideramos as variáveis utilizadas por Andreassen et al. (1998) para mensurar imagem, quais sejam: a) a opinião global sobre o sindicato; b) a opinião sobre a contribuição da instituição para a sociedade; e c) a admiração desfrutada pelo sindicato.

Destaque-se que os dados coletados são estatisticamente consistentes, já que a técnica de coleta inibe distorções e sazonalidades. De toda sorte, cabe explicitar um pouco melhor as características destes espaços amostrais e os mecanismos de abordagem aos inquiridos. Conforme já informado, o grupamento entrevistado é formado integralmente por indivíduos que realizaram atividades profissionais como metalúrgicos. Foram selecionados aleatoriamente entre empregados de 34 companhias onde foram aplicados originalmente 600 questionários dos quais 14 (quatorze) foram descartados por falhas de preenchimento e inconsistências diversas. Foram, então considerados válidos 586 questionários.

\section{Identidade e compromissos do sindicato dos metalúrgicos}

Conforme já explicitado o conceito aqui utilizado de identidade para uma organização diz respeito à auto identificação ou, por outra, a percepção que atores internos tem da organização da qual participam. Tal identidade ao mesmo tempo em que, internamente, é fator instituinte da cultura organizacional é a base de sustentação dos esforços coordenados de sua externalização e de criação da imagem através da a qual a corporação deseja ser percebida e identificada.

A definição precisa desta identidade e dos fatores que a determina, normalmente, implicaria no desenvolvimento de pesquisa prévia visando a análise da cultura organizacional do sindicato estudado. Contudo, no caso em tela, esta tratativa de interpretação foi realizada por meio de sondagem ao corpo dirigente do SINDMETAL.

Muito embora utilizando uma metodologia distinta daquela que seria convencional para este estágio da pesquisa exploratória aqui desenvolvida, a sondagem permitiu claramente que se determinasse a identidade presente no Sindicato dos Metalúrgicos estudado. Sumariamente, após a filtragem dos discursos analisados, a sondagem foi capaz de identificar não só os valores organizacionais, como também a mecânica de sua formação, os meios de sua evolução e os formatos de sua consolidação no estágio presente.

Destaque-se que, embora, estes valores organizacionais estejam presentes em todos os momentos e etapas de desenvolvimento da organização, não se apresentam de maneira estável ou permanecem perenes no que tange a sua relevância e importância relativa em termos da 'cultura' formadora de condutas. Em outras palavras, em cada fase da evolução do sindicato, valores específicos ganham destaque ao passo que outros (mesmo se mantendo vivos) perdem preponderância. Tal fenômeno é perfeitamente compreensível uma vez que a cada momento da progressão institucional um novo foco político é 
estabelecido implicando, necessariamente, na redefinição da hegemonia de valores.

O curioso - e relevante para a formação da identidade - é que por mais que se alternem em termos de seu destaque momentâneo, tais valores organizacionais jamais conflitam, por outro se complementam, compensam e equilibram, permitindo deste modo que o SINDMETAL assuma compromissos factíveis para com a categoria ao mesmo tempo que auxiliam e facilitam o processo de desenvolvimento institucional.

Dado os valores organizacionais presentes o SINDMETAL, tem para com seu público compromissos muito claros, relacionados a oferta de serviços com elevado padrão de qualidade e, principalmente, uma ação política compatível com a realidade e com as necessidades dos trabalhadores os quais representa. Para tanto, são também compromissos organizacionais: processos permanentes de revisão das condições de trabalho da categoria, modernização constante dos meios de divulgação e informação junto aos sindicalizados, promoção de serviços voltados para a garantia dos direitos trabalhistas e conscientização política do metalúrgico.

Com efeito, a identificação destes compromissos, a existência de valores organizacionais e a constatação de sua permanência ao longo do tempo possibilitaram a construção de um quadro analítico usado como referência para a construção de um perfil de identidade do SINDMETAL. Por seu turno, estes fatores expressos como valores pela citada sondagem foram incorporados ao inquérito realizado, uma vez que a imagem corporativa no sentido de impressão global e pública que se tem da organização é construída por um conjunto de inputs ou sinais liberados pelo sindicato, sendo que apenas parte deles derivam da identidade estabelecida, cabendo importância também a um conjunto amplo de ações, que promovidas sem a intenção de serem visíveis ou destinadas apenas para um público alvo previamente estabelecido, são amplamente perceptíveis pelo ambiente externo.

Destaque-se também que a imagem corporativa não se estabelece no curto prazo, pelo contrário, se consolida lentamente ao longo do tempo sendo, na prática, formada pelo conjunto de inputs que permanecem no inconsciente coletivo. Desta forma, diversos dos sinais emanados pela instituição, por mais regulares e frequentes que possam vir a ser, não necessariamente influenciam a impressão ou percepção que dela se estabelece junto ao público, ao passo que outras involuntárias, espasmódicas e, por vezes, indesejáveis, aderem de maneira permanente nesta percepção.

Assim, formulamos o seguinte esquema de teste que se caracteriza por prováveis fatores geradores de imagem, quer sejam eles determinados pela identidade, quer sejam pelos compromissos institucionais ou por inputs aleatórios: O Sindicato dos Metalúrgicos tem uma forte presença junto aos sindicalizados, por via de uma consistente ação política; O Sindicato dos Metalúrgicos tem sido bastante competente nas negociações salariais e na defaso dos interesses da categoria; O Sindicato dos Metalúrgicos presta relevantes serviços para a categoria profissional; Os serviços prestados pelo Sindicato dos Metalúrgicos, são de excelente nível se comparados com os prestados pelo poder público e, mesmo, os oferecidos pelas empresas contratantes; O Sindicato dos Metalúrgicos tem arcado com os custos destes serviços sem que possua efetivamente condições orçamentárias para tanto, o que lhe gera diversos problemas de ordem gerencial. Tais fatores foram testados pelo meio de questionário onde conjuntos de assertivas os caracterizam. 


\section{Análise dos dados}

Os dados derivados dos questionários de inquérito foram analisados por meio de técnicas estatísticas descritivas e multivariadas, com o auxílio do software SPSS for Windows. A ferramenta multivariada empregada compõem as análises fatoriais, que examinam a estrutura de covariância de um conjunto de variáveis e fornece uma explicação da relação entre essas variáveis em termos de um número menor de variáveis latentes ou dimensões, denominadas fatores, que contêm aproximadamente o mesmo montante de informação que o conjunto maior de observações originais.

Dada a finalidade do presente estudo, empregamos técnicas consagradas da análise fatorial (HAIR et al., 1998), com extração de componentes principais e rotação ortogonal, na qual é suposta a independência dos fatores. Na realidade, o nosso interesse primário foi verificar se a imagem corporativa participa da percepção do público em relação ao desempenho do Sindicato dos Metalúrgicos.

\section{RESULTADOS}

Apresentamos a seguir a análise dos dados gerados pelos cálculos estatísticos da amostra. Preliminarmente nos cumpre realizar, mesmo que de maneira breve, uma análise em forma mais técnica, para em seguida traduzir os dados em uma linguagem mais coloquial e menos rigorosa. Assim, tecnicamente podemos afirmar que a propriedade do emprego da análise fatorial foi comprovada, para o grupo analisado, pelo valor de 0,359 para a Measure of Sampling Adequacy (MSA), que superou o limite mínimo aceitável, segundo a obra citada de Hair et al. (1998).

Dando sequência aos testes prévios exigidos pelo método escolhido, realizamos o teste de esfericidade de Bartlett, que avalia a presença de correlações entre as variáveis, o qual também se mostrou significativo ao nível de $p<0,001$. De fato, o pesquisador deve certificar-se que a matriz de dados contém correlações suficientes para justificar a aplicação da análise fatorial, como no caso presente.

Quanto ao número de fatores que representaram a estrutura subjacente de dados, seguindo a orientação de Hair et al. (1998), o critério utilizado foi o de autovalores (eigenvalues) superiores a 1, o que supõe que qualquer fator individual deva ser responsável pela variância de pelo menos uma variável. A rotação simplifica a estrutura de fator, facilitando a sua interpretação. O caso mais simples de rotação é a ortogonal, na qual os eixos são mantidos em 90 graus. Esse procedimento significa que os fatores são matematicamente independentes. O VARIMAX foi o método de rotação ortogonal empregado, pois tende a gerar cargas elevadas, isto é, próximas de -1 ou 1, e algumas cargas próximas de zero em cada coluna da matriz, facilitando, dessa forma, a interpretação dos fatores.

De acordo com Hair et al. (1998), "não é incomum, nas Ciências Sociais, considerar satisfatória uma solução que responda por $60 \%$ (sessenta por cento) da variância total". Os cinco fatores obtidos com a pesquisa explicaram 77,36\% da variância total inicial. As comunalidades de todas as variáveis foram superiores a 50\% (cinquenta por cento). Ou seja, o montante de variância explicada pela solução de fator para cada variável superou o limite mínimo recomendado por Hair et al. (1998). As variáveis, as cargas 
fatoriais e os fatores relacionados à percepção do desempenho do Sindicato dos Metalúrgicos, cuja interpretação encontra-se descrita abaixo estão relacionados na Tabela a seguir.

Tabela: Rotated Component Matrix.

\begin{tabular}{|c|c|c|c|c|c|c|}
\hline & 1 & 2 & 3 & 4 & 5 & 6 \\
\hline Q3 - Negociação acordo 2018 bem conduzido & & & .735 & & & \\
\hline Q4 - Atuação positiva do Sindicato em 2018 extinguindo Com. Prévia Conciliação & & & .795 & & & \\
\hline \multicolumn{7}{|l|}{ Q5 - Banco de Horas é nocivo } \\
\hline & & & & .634 & & \\
\hline Q6 - Diretoria é eficiente na luta contra a terceirização & .669 & & & & & \\
\hline \multicolumn{7}{|l|}{ Q7 - Ação do Sindicato foi fundamental p/ geração de empregos no Setor Naval } \\
\hline \multicolumn{7}{|l|}{.637} \\
\hline Q8 - Colégio Metalúrgico traz benefícios e vale o investimento feito & & & & .615 & & \\
\hline \multicolumn{7}{|l|}{ Q9 - É boa atuação da CUT } \\
\hline \multicolumn{7}{|l|}{.732} \\
\hline Q10 - A CSC tem forte atuação na categoria & .583 & & & & & \\
\hline \multicolumn{7}{|l|}{ Q11 - Diretoria do Sindicato é eficiente na luta pelos direitos dos metalúrgicos } \\
\hline \multicolumn{7}{|l|}{.706} \\
\hline Q12 - Presidente do Sindicato age correta e com eficiência na defesa da categoria & .645 & & & & & \\
\hline \multicolumn{7}{|l|}{ Q13 - Depto. Jurídico é eficaz } \\
\hline & .737 & & & & & \\
\hline Q14 - Secretaria é ágil no atendimento & & .772 & & & & \\
\hline \multicolumn{7}{|l|}{ Q15 - Valor da mensalidade não é suficiente para o Sindicato exercer seu trabalho } \\
\hline & & & & & .589 & \\
\hline Q16 - Assistência médica gratuita é adequada & & & & & .580 & \\
\hline \multicolumn{7}{|l|}{ Q17 - Atendimento odontológico deveria ser igual ao atendimento médico } \\
\hline & & & & .744 & & \\
\hline Q18 - Contribuição financeira para ampliar atendimentos médico e odontológicos & & & & & & .806 \\
\hline \multicolumn{7}{|l|}{ Q19 - O Jornal é importante e tem informado satisfatoriamente } \\
\hline & & & .406 & & & \\
\hline Q20 - É correta a atitude em aproveitar as Delegacias apenas para atendimentos prioritários & & & & .436 & & \\
\hline \multicolumn{7}{|l|}{ Q21 - É importante elaboração de projetos específicos } \\
\hline & & & .778 & & & \\
\hline
\end{tabular}

Extraction Method: Principal Component Analysis. Rotation Method: Varimax with Kaiser Normalization.a Rotation converged in 16 iterations.

Agora, tentaremos aqui fazer o esforço de traduzir as informações acima para uma linguagem menos rebuscada e de mais fácil compreensão. O que o modelo de análise fatorial nos permite, quando acoplado a algumas ferramentas de ajuste, é aglutinar os vários inputs oferecidos pelo Sindicato dos Metalúrgicos ao público externo em grupos identificados como fatores. Estes fatores, na prática, tomam nas suas mais diversas formas os sinais, emanados pela organização e que foram testados pela pesquisa e os associam, ou seja, os agrupam sinergicamente. Em outras palavras, identifica quais inputs mantém relações entre si. Tais relações mútuas constituem uma fonte de imagem que a organização é capaz de transmitir.

O modelo estatístico constituiu quantos fatores - ou se preferirmos, grupos de sinais que juntos (e apenas juntos) definem a percepção do púbico sobre a organização ou sobre sua imagem corporativa quantos forem necessários para 'explicar' os resultados obtidos na amostra. Para o caso de nossa pesquisa quanto a imagem que o Sindicato dos Metalúrgicos transmite para os trabalhadores da categoria, o modelo constitui 6 (seis) fatores ou, se preferirmos, seis blocos de sinais mutuamente associados que se constituem em fontes geradoras de imagem.

Para a amostra testada, estes 6 (seis) fatores explicam 77,36\% da variância total inicial. Sabendo-se que a variância é uma medida de dispersão, o que o modelo de análise fatorial efetivamente faz é 'acumular' as variáveis dispersas criando uma 'solução' por via dos fatores constituídos que gere relevância significativa quanto à percepção que os elementos inquiridos na pesquisa têm sobre o Sindicato dos Metalúrgicos. Com 
efeito, os 6 (seis) fatores criados pelo modelo são equivalentes à seis imagens que aquele público pesquisado constituiu e, principalmente, consolidou quanto a organização. Sendo estas imagens condizentes com um determinado conjunto de sinais que a organização emitiu (voluntariamente ou não) para fora de seus muros.

É possível compreender que cada uma destas imagens (expressas pelos fatores) tem graus diferentes de penetração e consolidação junto ao público, sendo que o fator 1 expressa a imagem mais arraigada e, provavelmente, a mais difundida, enquanto o fator 6 representa a de menor relevância, uma vez que os cálculos realizados pelo SPSS, indicam que o primeiro fator sozinho explica $24,20 \%$ da variância total inicial ao passo que o fator 6 se limita a explicar 10,58\% dela. Com base nestas informações passamos a interpretar os dados lançados no quadro abaixo, que associa as variáveis testadas e suas cargas fatoriais com os fatores relacionados à Percepção da Imagem do Sindicato dos Metalúrgicos. O quadro abaixo reorganiza as variáveis agrupando-as aos fatores que constitui.

Quadro
\begin{tabular}{|l|l|l|l|l|}
\hline Fator 1 & Fator 2 & Fator 3 & Fator 4 & Fator 5 \\
\hline $\begin{array}{l}\text { Ação do SINDMETAL } \\
\text { em defesa do emprego } \\
\text { e do direito dos } \\
\text { metalúrgicos }\end{array}$ & $\begin{array}{l}\text { Eficiência no } \\
\text { atendimento as } \\
\text { necessidades e de } \\
\text { apoio legal ao } \\
\text { trabalhador }\end{array}$ & $\begin{array}{l}\text { Eficácia nas } \\
\text { negociações } \\
\text { salariais }\end{array}$ & $\begin{array}{l}\text { Qualidade de serviços } \\
\text { complementares para a } \\
\text { categoria }\end{array}$ & $\begin{array}{l}\text { Qualidade dos } \\
\text { atendimentos } \\
\text { médicos e } \\
\text { odontológicos }\end{array}$ \\
\hline $\begin{array}{l}\text { Envolvimento com o } \\
\text { movimento sindical e a } \\
\text { conscientização política } \\
\text { da categoria }\end{array}$ & & $\begin{array}{l}\text { Necessidade de } \\
\text { ampliação dos valores } \\
\text { arrecadados para } \\
\text { manter a qualidade } \\
\text { dos serviços }\end{array}$ \\
\hline
\end{tabular}

Verifica-se, assim, que 2 (duas) variáveis formam o fator 1 . Uma vez que estas variáveis representam sinais difundidos pela organização e como já explicitado, o fator 1 é o de maior relevância, podemos afirmar que a principal imagem que o grupo de trabalhadores da categoria constrói do Sindicato dos Metalúrgicos diz respeito fundamentalmente aos aspectos da ação política do SINDMETAL, seu envolvimento com o movimento sindical nacional e sua capacidade de agir junto as metalúrgicos com o intuito de elevar seu grau de consciência enquanto trabalhadores e cidadãos.

Esta visão de ser um ator político comprometido com a categoria e com as questões nacionais, se coaduna com a identidade e com o compromisso estabelecido, caracterizando-se como uma imagem favorável que delimita claramente o perfil do Sindicato dos Metalúrgicos, estabelecendo seu atributo preferencial e, por conseguinte, sua conduta organizacional mais adequada. A imagem aqui constituída da conta de que o desempenho político recente do Sindicato dos Metalúrgicos vem sendo mais do que satisfatório, é exitoso.

Examinando o fator 2, verifica-se que além da imagem de um sindicato que opera com referências claras quanto as necessidades da categoria e que dá apoio as demandas dos trabalhadores com eficácia e rapidez, assim o Sindicato dos Metalúrgicos construiu perante aos metalúrgicos a imagem de apoiar os trabalhadores em demandas legais, trabalhistas e administrativas. Tal imagem, todavia, é constituída muito mais como subproduto dos resultados obtidos pela área jurídica do Sindicato dos Metalúrgicos do que por outras vias de conduta regular, implicando, portanto, numa percepção que tende a se dissolver quando, eventualmente, cessada ou modificada as vitórias em contendas judiciais. 
Tal imagem estabelecida permite avaliar positivamente os esforços e dispêndios atuais do Sindicato dos Metalúrgicos, uma vez que aparentemente a organização consegue difundir (embora não se tenha parâmetro, no momento, para afirmar se é capaz de consolidar) o compromisso em primar na defesa dos direitos dos metalúrgicos com padrão de qualidade e rapidez.

O fator 3, é fortemente influenciado pela percepção de renda individual dos metalúrgicos, uma vez que é composto por variáveis relativas aos acordos coletivos de trabalho. Embora seja indicada como uma referência até certo ponto positiva no que se refere a ação do Sindicato dos Metalúrgicos, evidencia que os trabalhadores não estão satisfeitos com suas remunerações e que acreditam merecerem melhores condições profissionais. Tal assertiva se confirma pela baixa relevância apontada no quesito 'banco de horas' (que constitui o fator 5), visto que não parecem se importar com o tema, vez que, na falta de melhores condições, implica para a opinião média em vantagem remunerativa.

Tal reputação de eficácia nas negociações salariais embora de relevância muito menor que as duas anteriores significam que para um seguimento de indivíduos inquiridos o Sindicato dos Metalúrgicos oferece ou possui um potencial de negociação que o credencia e legitima para tais negociações, embora, aparentemente, se considere que há espaço para a ampliação das conquistas nesta área de atuação.

O fator 4 está relacionado a ação do Sindicato dos Metalúrgicos no sentido de gerar projetos específicos, diversificar os pontos de atendimento e de propiciar um eficaz sistema de comunicação com a categoria. Com efeito, estes elementos constitutivos do fator, estão diretamente relacionados aos anteriores, ficando clara sua complementaridade com a ação política do sindicato. Destaque-se que aqui, em algum sentido distorcendo o fator, encontra-se também a imagem do Colégio Metalúrgico, compreendido com um símbolo da categoria e que, provavelmente, é visualizo com uma ideia interessante que deve ser preservada, mas que tem pouca utilidade individual, mesmo porque sua oferta está condicionada a um conjunto de limitações, inclusive geográfica.

Por seu turno, o fator 5 que diz respeito a reputação quanto aos demais serviços prestados e, mesmo, ampliação e modernização destes serviços. Nestes termos, embora o Sindicato dos Metalúrgicos mantenha a imagem de um sindicato que pratica uma política de geração de serviços para a categoria e que está atenta as novas necessidades dos trabalhadores é vista como uma organização que oferece relativamente poucas vantagens se comparadas com o seu potencial e, mesmo, de serviços prestados por outros agentes, quer público, quer privado. Note-se que o trabalhador metalúrgico não possui conhecimento claro das dificuldades da oferta desses serviços e tem a sensibilidade de que encontrará atendimentos mais qualificados em instancias que se dedicam exclusivamente a estas atividades. Deste modo, embora considerando importante, a categoria vê como de pouca qualidade o atendimento médico odontológico oferecido.

Finalmente, o fator 6 que estabelece a reputação de que o Sindicato dos Metalúrgicos necessita de um maior aporte de recursos financeiros para ampliar os serviços que presta e, mesmo, sua ação política, embora exista, é uma imagem pouco consolidada, denotando, por um lado, que aos olhos dos trabalhadores, o sindicato já obtém e se beneficia de recursos suficientes providos pela Contribuição Sindical e, mesmo, por 
outro, que os graus de 'exigências' financeiras da entidades não são tão significativas, sendo que qualquer aumento de contribuições ou mensalidades são, verdadeiramente, vistas com pouca boa vontade, caracterizando um empecilho para a efetivação da ampliação dos serviços.

De toda sorte a baixa relevância do fator associada à alta significância dos fatores anteriores confirmaria a hipótese de que para os metalúrgicos as escolhas realizadas pela atual diretoria têm se demonstrado corretas e são dignas de apoio. Por conseguinte, parece-nos razoável aceitar que mediante um procedimento transparente de apresentação das necessidades, há a possibilidade de efetivação de campanhas específicas objetivando a elevação da arrecadação, desde que condicionadas a redução das limitações por que, eventualmente, passa o Sindicato dos Metalúrgicos já que a categoria demonstra um forte interesse em ampliar o portfólio de serviços de seu sindicato.

\section{CONCLUSÕES}

A pesquisa realizada apresenta claramente a imagem corporativa que o Sindicato dos Metalúrgicos hoje possui junto a categoria profissional. Tanto é assim, que no grupo examinado os fatores determinantes mais relevantes para a formação das impressões globais coincidem com pouquíssimas nuances com a identidade que foi estabelecida por sua Diretoria.

Evidencia-se, assim, que a imagem corporativa do Sindicato dos Metalúrgicos se consolida nitidamente nos fatores principais e tende a se dispersar nos menos representativos. Com efeito, podemos afirmar que reside na seriedade e competência da ação política e no verdadeiro interesse de buscar atender as necessidades da categoria, a imagem corporativa do SINDMETAL.

Note-se, assim, que a imagem mais nítida do Sindicato dos Metalúrgicos é de um sindicato que preza a qualidade dos serviços que oferecem e que mantém um elevado padrão político. Neste sentido e na medida em que está reputação coincide com vários dos compromissos enunciados pela Diretoria, o mais adequado a fazer é fortalecer esta imagem.

Todavia, a sugestão mais imediata a ser feita diz respeito ao fortalecimento dos elementos constantes no nível intermediário na matriz de imagem, o que pode ser alcançado de várias formas além do óbvio esforço de comunicação junto aos trabalhadores. Para alcançar estes objetivos, cabe ao Sindicato dos Metalúrgicos estimular a manutenção da identidade vivenciada pelos atores que dela participam e perseguir os compromissos já estabelecidos, assim será capaz de ampliar seu desempenho atual em termos de atendimento as demandas, eficiência alocativa e manutenção de seus compromissos políticos.

\section{REFERÊNCIAS}

ALESSANDRI, S. W.. Modeling corporate identity: a concept explication and theorical explanation. Corporate

Comunications: An International Journal, v.16, n.4, p.173-

182, 2001a. DOI:

https://doi.org/10.1108/EUM0000000006146

ALESSANDRI, S. W.. Projecting and Protecting Corporate Identity on the Web: An Exploration of Companies of Varying Size, 2001b.
ANDREASSEN, T. W.; LINDESTAD, B.. Customer loyalty and complex services, International Journal of Service Industry Management, v.9, n.1, p.7-23, 1998. DOI: https://doi.org/10.1108/09564239810199923

ANDREASSEN, T. W.; LINDESTAD, B.. Customer loyalty and complex services: The impact of corporate image on quality, customer satisfaction and loyalty for customers with varying 
degrees of service expertise. International Journal of Service Industry Management, v.9, n.1, 1998. DOI:

https://doi.org/10.1108/09564239810199923

BALMER, J. M. T.. Corporate identity, corporate branding and corporate marketing: seeing through the fog. European Journal of Marketing, v.35, n.3-4, p.248-291, 2001. DOI: https://doi.org/10.1108/03090560110694763

CARUANA, R.. Multitask Learning: A Knowledge-Based Source of Inductive Bias. In: INTERNATIONAL CONFERENCE ON MACHINE LEARNING, 10. Anais. Amherst: University of Massachusetts. p.41-48.

FOMBRUN, C.; SHANLEY, M.. What's in a Name?. Reputation Building and Corporate Strategy The Academy of Management Journal, v.33, n.2, p.233-258, 1990. DOI: https://doi.org/10.2307/256324

GOTSI, M.; WILSON, A.. Corporate reputation management: 'living the brand'. Management Decision, v.39, n.2, p.99104,

2001. DOI: https://doi.org/10.1108/EUM0000000005415

HAIR, J.; ANDERSON, R.; TATHAM, R.; BLACK, W. Multivariate Data Analysis. Upper Saddle River: PrenticeHall, 1998.

MARTINEAU, P.. Social Glasses and Spending Behavior. Research Article, v.23, n.2, 121-130, 1958 DOI: https://doi.org/10.1177/002224295802300201

VERGARA, S.. Projetos e relatórios de pesquisa em administração. São Paulo: Atlas, 2009.

A CBPC - Companhia Brasileira de Produção Científica (CNPJ: 11.221.422/0001-03) detém os direitos materiais desta publicação. Os direitos referem-se à publicação do trabalho em qualquer parte do mundo, incluindo os direitos às renovações, expansões e disseminações da contribuição, bem como outros direitos subsidiários. Todos os trabalhos publicados eletronicamente poderão posteriormente ser publicados em coletâneas impressas sob coordenação da Sustenere Publishing, da Companhia Brasileira de Produção Científica e seus parceiros autorizados. Os (as) autores (as) preservam os direitos autorais, mas não têm permissão para a publicação da contribuição em outro meio, impresso ou digital, em português ou em tradução. 